\title{
Influence of Demographic Characteristics, Rice Cultivation Methods, and Value Chain Attitude on Operational Efficiency of the Organic Rice Industry in Thailand
}

\author{
Pensri Jaroenwanit ${ }^{1}$, Piyada Daowadueng ${ }^{2}$, Patcharee Hongthong ${ }^{3}$ \\ \{penjar@kku.ac.th ${ }^{1}$ \} \\ Faculty of Business Administration and Accountancy, Khonkaen University, Thailand ${ }^{1.2 .3}$
}

\begin{abstract}
This research has the objective to study demographic characteristics, organic rice cultivation methods and value chain attitudes on operational efficiency of the organic rice industry in Thailand. The study was conducted from a sample of 300 participants involved in the organic rice industry in Thailand. Data were analyzed by using statistical packages (SPSS) including confirmation element analysis (CFA), path analysis and structural equation model analysis (SEM). The results of the study demonstrate that the demographic characteristics of the farmers, organic rice cultivation methods and value chain attitudes influence operational efficiency of the organic rice industry in Thailand.
\end{abstract}

Keywords: Value chain, organic rice, operational efficiency, competitive competency

\section{Introduction}

The value chain is a new dimension in developing and driving today's economy and society. By implementing the value chain for various operations in the organization, it will create added value for raw materials from the raw materials, which go through the conversion process, to ready-to-market products, delivered to customers, which all rely on the entire operational value chain [11]. In Thailand, the studies on the value chain have been started since 1, but they are not yet widespread. In addition to increasing the productivity, the value chain also improves operational efficiency [3], which can facilitate the farmers to produce more profitable organic rice. This will benefit all parties involved, including raw material producers, processors, distributors, and, of course, consumers. As a result, the researchers desire to study the value chain influencing operational efficiency of the organic rice industry in Thailand for further industrial and academic benefits.

\section{Literature review}

Demographic concepts [7] explain that demographic concepts are the individual characteristics with differences in individual characteristics and qualifications, and can be identified as gender, age, income, and different educational backgrounds. This different 
demography results in individually different behavior, thoughts and attitudes, which are related to other operational factors. More recently, [6] it was found that demographic characteristics influenced operational efficiency. In the research, it was found that age, gender and education were consistent with the operational efficiency of the farmers. In addition, demographic diversity influences the implementation of a company's strategy. In term of agriculture, it was found in a recent study [2], which examine demographic characteristics and attitudes of smallscale vegetable growers in Chile. It was found that different attitudes were consistent with demographic characteristics, such as age, education, farm size and technology. The farmers who are old, low-educated and limited in use of technology have lower operational efficiency than those who are young and high-educated as measured by the sales produced per square meter.

The concept of organic rice cultivation methods [5] explains that organic rice cultivation methods by farmers in each area have different cultivation methods according to demography, topography, farmer's experience including cost factors and the use of technology in cultivation. Since organic rice cultivation avoids the use of chemical fertilizers and has soil fertility management, which is a delicate rice cultivation with emphasis on the use of natural materials, avoiding synthetic raw materials including plants, animals or microorganisms derived from genetic modification techniques. This makes organic rice cultivation different from general industrial rice cultivation. More recently, [12] the studies on organic rice cultivation methods of farmers influencing operational efficiency, which explain that smart cultivation methods and the use of useful technology by farmers enable them to work more efficiently, resulting in better quality organic rice production. Similarly, a study of [13], which investigated factors influencing decision-making and operational efficiency of farmers supported by enterprise groups in Satuek District, Buriram Province, Thailand. It was found that cultivation characteristics and methods of the farmers were related to operational efficiency of farmers as well.

The concept of value chain [8] explains the value chain as an activity that occurs both internally and externally from the procurement of raw materials and processing to the delivery of goods and services [3]. More recently, value chain analysis studies have been conducted to contribute to the competitive advantage of [1], in line with the study by [9], which found that organic rice value chain is system-centered, with a variety of connections that link the process of centralized organic rice farmers as a strong network, resulting in sustainability influencing operational efficiency of the farmers. A similar study by [10] studied business strategy planning using value chain analysis, and it was found that value chains contribute to purchasing and management of materials, exports, infrastructure, marketing and sales, as well as services and other supports, considered as a great help in increasing the competitiveness of the organization.

Conceptual framework used in research; from literature reviews on concepts, theories and related research, the researchers can summarize and build a conceptual framework used in research as follows showed Figure 1. 


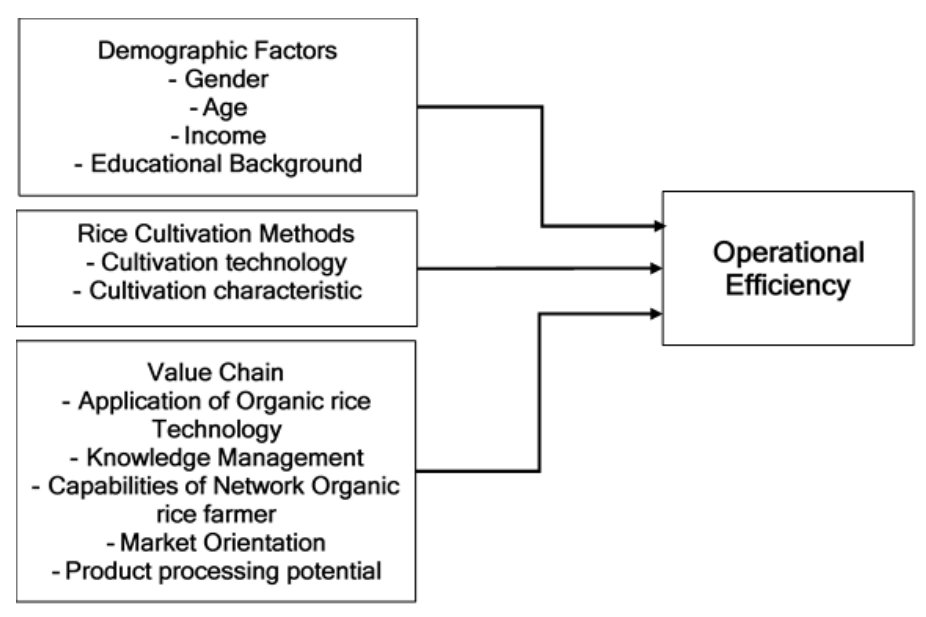

Fig. 1. Conceptual framework

\section{Method}

The population includes those who are stakeholders in the organic rice industry in the northeast of Thailand and community enterprises in the area of RoiKaenSaraSin participated in the project in the total of 300 samples. Purposive sampling was used to identify the sample group in the northeast of Thailand's organic rice chain, and questionnaires are used as a research instrument. The self-administered questionnaire was divided into 4 parts in which the respondents were able to answer the questionnaire by themselves including part 1 (respondent's general information), part 2 (agricultural information), part 3 (opinions on the value chain), and part 4 (opinions on operational efficiency).

Data analysis was done by collecting data from the questionnaire to verify the completeness of the information obtained. The data were processed by SPSS to obtain statistics used in 4-step data analysis: (1) model analysis, measurement and the analysis of accuracy and reliability using confirmatory factor analysis to determine the element weight to show variables influencing operational efficiency, (2) path analysis to analyze the influence or cause of the independent variable affecting the dependent variable, and (3) structural equation modeling which is a hypothesis analysis technique between multiple independent variables at the same time.

\section{Results and Discussion}

\subsection{Results}

Demographic data of the sample: most of the respondents were male $(60 \%)$, aged around 31.35 years old $(32.7 \%)$. The highest educational background is high school or equivalent, $(42.7 \%)$. Monthly income is between $15,001-25,000$ baht $(57.3 \%)$. Most career is personal business $(52.7 \%)$. 
Data on organic rice cultivation methods: most farmers have agricultural and residential areas in the total of 30 rai and 40 rai $(28.6 \%)$. A living area includes 1 rai or $65.7 \%$. An area for rice cultivation includes 20 rai or $31.4 \%$. An area of horticultural cultivation includes 4 rai or $37.5 \%$. A cultivation area includes 10 rai or $33.3 \%$. An area for fruit and perennial cultivation includes 100 rai or $100.0 \%$, and most of them have not been certified for production standards, accounting for $57.1 \%$ and passed the production standard certification, accounting for $42.9 \%$. Most of respondents have mobile phones, accounting for $100.0 \%$. Android users are accounted for $100.0 \%$. Most of them do not have computers, accounting for $100.0 \%$. They have the objective of the use of information technology to chat and communicate, accounting for $100.0 \%$.

Data for enterprises: most of respondents currently have 6 employees or $25.7 \%$. There are 2 temporary employees or $17.1 \%$. A sole proprietorship is accounted for $68.0 \%$. Most of business groups are trade, service and agriculture sectors, all accounting for $33.3 \%$. Most of them do not have mobile phones, accounting for $68.0 \%$ while those who have mobile phones using Android OS, accounting for $70.8 \%$. Most of them do not have computers within the organization, accounting for $81.3 \%$. Notebooks are accounted for $21.3 \%$. Intranet is used as a network in the organization, accounting for $85.3 \%$, Package software is accounted for $65.3 \%$. The main objective in the use of information technology is to search for information, accounting for $66.7 \%$.

\subsubsection{Pearson's correlation analysis}

From Table 1, when considering the relation of the value chain, it was found that operational efficiency and network capability had the highest correlation coefficient of .775, followed by technological application and knowledge management, with a correlation coefficient of .768 , while market orientation and operational efficiency had the lowest correlation coefficient of .583 .

Table 1. Value chain correlation coefficient matrix on operational efficiency

\begin{tabular}{lllllll}
\hline Variables & $\mathbf{1}$ & $\mathbf{2}$ & $\mathbf{3}$ & $\mathbf{4}$ & $\mathbf{5}$ & $\mathbf{6}$ \\
\hline Technological Application & 1 & & & & & \\
Knowledge Management & $.768^{* *}$ & 1 & & & & \\
Network Capability & $.752^{* *}$ & $.716^{* *}$ & 1 & & & \\
Market Orientation & $.647^{* *}$ & $.686^{* *}$ & $.625^{* *}$ & 1 & & \\
Product Processing Potential & $.739^{* *}$ & $.692^{* *}$ & $.690^{* *}$ & $.621^{* *}$ & 1 & \\
Operational Efficiency & $.761^{* *}$ & $.766^{* *}$ & $.775^{* *}$ & $.583^{* *}$ & $.721^{* *}$ & 1 \\
\hline
\end{tabular}

Note $* \mathrm{p}<.05$ is statistically significant at .05 .

\subsubsection{The analysis of the influence on the value chains on operational efficiency}

From Table 2, it was found that technological application of the organic rice value chain, knowledge management of the organic rice value chain, network capability of the organic rice, marketing orientation of the organic rice value chain, product processing potential of the organic rice value chain were causally correlated to operational efficiency according to the hypothesis. 
Table 2. Characteristics of casual influence on relation between value chains on operational efficiency

\begin{tabular}{|c|c|c|}
\hline \multirow{2}{*}{ Measurement } & \multicolumn{2}{|l|}{ Test Results } \\
\hline & Influence & Total \\
\hline $\begin{array}{l}\text { Technological application of the organic rice value chain was positively } \\
\text { correlated to operational efficiency. }\end{array}$ & $\begin{array}{l}\mathrm{DE}=.298^{*} \\
\mathrm{IE}=.544^{* *}\end{array}$ & $\mathrm{TE}=.842^{* *}$ \\
\hline $\begin{array}{l}\text { Knowledge management of the organic rice value chain was positively } \\
\text { correlated to operational efficiency. }\end{array}$ & $\begin{array}{l}\mathrm{DE}=.616^{* *} \\
\mathrm{IE}=.329^{*}\end{array}$ & $\mathrm{TE}=.945^{* *}$ \\
\hline $\begin{array}{l}\text { Network capability of the organic rice was positively correlated to } \\
\text { operational efficiency. }\end{array}$ & $\begin{array}{l}\mathrm{DE}=.453^{*} \\
\mathrm{IE}=.400^{*}\end{array}$ & $\mathrm{TE}=.853^{* *}$ \\
\hline $\begin{array}{l}\text { The market orientation of the organic rice value chain was positively } \\
\text { correlated to operational efficiency. }\end{array}$ & $\begin{array}{l}\mathrm{DE}=.503^{* *} \\
\mathrm{IE}=.342^{*}\end{array}$ & $\mathrm{TE}=.845^{* *}$ \\
\hline $\begin{array}{l}\text { Product processing potential of the organic rice value chain was } \\
\text { positively correlated to operational efficiency. }\end{array}$ & $\begin{array}{l}\mathrm{DE}=.365^{*} \\
\mathrm{IE}=.593^{* *}\end{array}$ & $\mathrm{TE}=.958^{* *}$ \\
\hline
\end{tabular}
Note $* \mathrm{p}<.05$ is statistically significant at .05 .

\subsubsection{Structural equation modeling}

The researchers have analyzed the relation between the variables in the model by path analysis, which is a concept that can analyze data through structural equation modeling. It was found that a model that demonstrated the relation between variables using the Maximum likelihood estimation method used developed package software, as shown in the Table 3.

Table 3. Results of the consistency of the path analysis on structural equation modeling

\begin{tabular}{llll}
\hline Statistics & Measurement & Outcome & Results \\
\hline$\chi^{2}$ & - & 2.27 & - \\
$d f$ & - & 1 & - \\
$\chi^{2} / d f$ & Less than 3.00 & 2.47 & Passed \\
$p$ & More than .05 & .120 & Passed \\
CFI & More than .90 & .986 & Passed \\
GFI & More than. 90 & .977 & Passed \\
RMSEA & Less than .08 & .056 & Passed \\
SRMR & Less than .08 & .019 & Passed \\
\hline
\end{tabular}

Note $^{*} \mathrm{p}<.05$ is statistically significant at .05 .

The fit between the model and the empirical data is considered by the given the statistical value, $\chi^{2} / d f$, which should be less than 3.00. The probability value of the matrix test of variance in the model estimated with empirical data must exceed the statistical significance level of .05 ( $p>.05)$. Then, it is accepted that the model is fit with the data. However, the fit index value must be greater than .90 , namely goodness of fit index (GFI), comparative fit index (CFI), and the non-fit or residual index must be less than .08, namely RMSEA, the root means square error of approximation (RMSEA) and standardized root mean squared residual (SRMR). The results indicated that the correlation model between variables was fit with the empirical data, where statistical values passed all of the criteria.

\subsection{Discussion}

The study on demographic characteristics, organic rice cultivation methods and value chain attitude on operational efficiency of the organic rice industry in Thailand establishes an understanding of organic rice cultivation characteristics, methods and improved perspective of 
farmers. The results of the study demonstrate that demographic characteristics, organic rice cultivation methods and value chain attitude on operational efficiency can effectively predict phenomena and consequences for further modification and improvement of operational efficiency among organic rice farmers in Thailand. In addition, this study reveals the fact that the value chain positively affects operational efficiency, resulting in academic benefits. This leads to further studies on the value chain, which can lead to a further movement in academia and branching out of knowledge.

The results of this study found that the value chain is an activity that brings products and services from the start to the final stage in delivery to the consumer through various stages. The goal is to deliver the highest value at every stage to the consumer with minimal cost. The appropriate allocation of value chain resources can increase income even more. This shows that the value chain and competitiveness are correlated. Strengthening the value chain at all stages, it can ensure confidence in competitiveness, in line with the previous research study by [5], which found the value chain is an activity consistent with operational efficiency of farmers, resulting in more efficient in operational efficiency. It was also found in the research by [4] and, similarly, [3], which found that the value chain was a factor that contributes to operational efficiency among farmers. When farmers develop their production potential based on the principles of the value chain, they will progress in modernizing the cultivation methods until it becomes acceptable to compete at a higher level. This will increase operational efficiency including more income accordingly.

\section{Conclusion}

From the analysis results, it can be concluded that, from the perspective of farmers on the importance of organic rice cultivation methods and activities in the organic rice value chain that contribute to operational efficiency, organic rice value chain, technological application of the organic rice value chain, knowledge management of the organic rice value chain, network capability of the organic rice, market orientation of the organic rice value chain and product processing potential of the organic rice value chain will increase the group's operational efficiency. As farmers have many competitors to distribute organic rice, this organic rice value chain is primarily necessary to improve their operational efficiency.

\section{References}

[1] A. Razak and K. Vattikoti, "Critical Evaluation of Value Chain Analysis for Assessing Competitive Advantage-A Study on Select Companies of E-Tailing Industry," Academy of Strategic Management Journal, (Print ISSN: 1544-1458; Online ISSN: 1939-6104),2018 Vol: 17 Issue: 6, 2018.

[2] B. Sofia, C. Maruja, P., Carmen, T. Eulogio, and M. Marcos, "Characteristics and attitudes of smallscale vegetable farmers in Chile," Ciência Rural, 50(10), e20191025. Epub August 28, 2020.

[3] F. Subarna \& I. Mitsuru, "Value creation and competitive advantages for the Shrimp industries in Bangladesh: A value chain approach," Journal of Agribusiness in Developing and Emerging Economies, 8. 00-00. 10.1108/JADEE-04-2017-0048, 2018.

[4] F. Andria, S. Hartini, A. Rahmi and E. Rusmanah, "Effect of Operations Capabilities on Financial Performance of Firms with Moderating Role of Supply Chain Management Capabilities: A case of Indonesian Pharmaceutical Firms," SystematicReview Pharmacy, Vol 11, Issue 1, Jan-June, 2020. 
[5] J. Hendro \& P. Cindy and H. Herdis, "Organic rice farming: an alternative to sustainable agriculture," IOP Conference Series: Materials Science and Engineering, 546. 022008.10.1088/1757899X/546/2/022008, 2019.

[6] J. Tapio, "Top management team demography and firm operating performance: a path analysis," Journal of Strategy and Management, ahead-of-print, 10.1108/JSMA-12- 2019-0224. 2020

[7] K. Martin, "Demographic Theory and Population Ethics -Relationships between Population Size and Population Growth," The Institute for Futures Studies, vol.11, pp.245-272, 2019.

[8] M. Porter, "Competitive Advantage of Nations: Creating and Sustaining Superior Performance," Free Press, Illustrated edition, May 31, 2011.

[9] S. Quiédeville, J. Bassene, B. Lançon, F. Chabrol and D. Moustier, "Systemic Sustainability of the French Organic Rice and PGI Einkorn Value Chains: A Preliminary Assessment Based on Network Analysis," Sustainability, 10, 2344, 2018.

[10] S. Jarmila \& I. Rajiani, \& P. Petra \& V. Jan and D. Ján, "Use of the Value Chain in the Process of Generating a Sustainable Business Strategy on the Example of Manufacturing and Industrial Enterprises in the Czech Republic," Sustainability, 12. 1520, 2020.

[11] T. Anita \& M. Dario \& A. Niksa \& P. Jurica, "Market Orientation, Competitive Advantage and Business Performance: Exploring the Indirect Effects," Drustvena istrazivanja, 26. 10.5559/di.26.4.07, 2017

[12] T. Liliane and M. Charles, "Factors Affecting Yield of Crops, Agronomy - Climate Change \& Food Security," 2020.

[13] A. Intech Open and W. Sareeya. "A Critical Assessment of Organic Rice Farming: Factors Affecting Farmer's Decision and Performance (A Case Study of Rice Farmers Supported by a Social Enterprise," 2019. 